\title{
Annotation
}

\section{Consent for children and adolescents who have an intellectual handicap}

Every day paediatric practice probably raises a few queries concerning consent. Parents give their consent by proxy, based on what they believe is best for their child, determined largely by medical information and family custom. But there are several well known conundrums: there is the child with no living parents, the abandoned, handicapped child in the long stay hospital, the child in foster care, and the child who is at risk from his own family. There is also the child who cannot have blood transfusions for religious reasons. An unaccompanied minor is the term for a child refugee who may well have parents but in the havoc of war has become detached and is alone in a foreign country. Most of these situations are resolved by relying on precedent, and in the minority, by the use of legal procedures such as wardship or reception into care.

\section{Current dilemmas concerning consent}

Several incidents in the last 10 years have caused concern. There is the debate on how much information is necessary for consent to be fully informed, the question of minors who wish to give consent for contraception but expect confidentiality, and the dilemma of those who have reached their majority but remain unable to consent because of intellectual handicap. ${ }^{1}$ Then there is the question of who can consent when the operation has eugenic overtones, such as sterilisation or abortion of both minors and adults who are unable to consent.

\section{The child with intellectual handicap}

Consent by proxy from caring parents will be the norm for intellectually handicapped children under 16 years, but if necessary the child can be made a ward of court or be received into care. While the procedures are no different for the handicapped child and his or her parents, there may be particular difficulties because of the presence of handicap. Parents, for example, may have difficulty in deciding to consent to a life saving operation on a multiply handicapped child, either at birth or later on. The outcome of standard surgical or medical intervention may be unclear because of the handicaps or parents may be asked for permission to involve their handicapped child in research procedures. Perhaps the most iniquitous of all is that they may be asked to sign a compulsory prospective 'cover all' consent form if their child is admitted to residential care, either for respite or permanently. These forms, of doubtful validity, cover anything from emergency medical treatment to horse riding and effectively pass day to day decision making to the professional care givers, who thus become both judge and jury.

The well versed non-accidental injury procedures do not always apply to handicapped children, partly because the norms of adequate care are often unclear and also because there may be no alternatives to parental care. The author well remembers a 14 year old child who had been trussed for days on the floor of the family home as the only means to stop him biting others. Despite every effort no procedure for non-accidental injury followed as it was known that hospital care was unacceptable to the family and no other facility was available.

\section{Consent and legal competence}

The law states that at 16 years the adolescent may be considered autonomous and legally competent to make decisions for himself, but the 16th birthday should be considered only as a mean age for the development of those decision making powers. Some will be competent earlier and some later and simple decisions will be made earlier than complex ones. Perhaps the 16 plus child is allowed his choice when this accords with parental wishes but not when it doesn't! However, others over 16 with intellectual handicap may never develop the understanding necessary for consent and it is on this last group that the spotlight has now been focused. Parental consent becomes invalid in law at the age of 16 years but no one else can give legally valid consent. This 
vacuum in the law is relevant to those with developmental intellectual handicap, those with severe head injuries, and those damaged by long standing mental illness or dementia. ${ }^{2}$

\section{The search for a solution}

The Mental Health Act (1959) dealt with involuntary detention in hospital and provided safeguards for mentally ill and mentally handicapped people so detained, as well as facilitating the development of community care. The sections on treatment without consent related to mental illness only.

This act of 1959 repealed a long series of acts to do with mental illness and intellectual handicaps, and in so doing the act revoked the Royal Prerogative whereby the Sovereign could act as 'parens patriae' and could issue a warrant to allow someone who was legally incompetent to receive necessary treatment or management. The last Royal Warrant was so issued in 1960.

It was hoped that the guardianship order in the 1959 act, a new concept in care, might take the place of that Warrant. The guardian (who could be a parent) was expected to treat the handicapped person as a young teenager and could sign consent forms on his behalf in addition to undertaking other parental duties. Very few guardianship orders were effected as prospective guardians were usually personnel of social services and the workload was seen to be substantial. In addition the law was little understood by parents who saw no reason to apply to be guardians as they continued to sign consent forms, which were acceptable to those who required them, neither party knowing that the system was of no legal standing. This mistake was often compounded by the use of a paediatric type of consent form, thus adding infantilism to invalid paternalism.

The Mental Health Act (1983) which replaced the 1959 act, produced restrictions on the role of guardians who could no longer sign consent forms, and the group of people with intellectual handicap, eligible for guardianship, was now limited to those who had abnormally aggressive or seriously irresponsible behaviour, the so called mentally impaired.

The National Assistance Act (1948) Section 47 can only be used to remove adults from their home against their will when there is total squalor in their living conditions and usually remediable illness. This act therefore has nothing to offer in the debate on consent.

The Court of Protection rules have been examined but this was set up to provide financial management for those who could not be personally responsible for their own affairs.

Neither does it seem sensible to rely on the 'double negative' declaration that a judge can give, that it would 'not be unlawful' to proceed with medical intervention. This is a way around the accusation of 'battery' that might follow if there is no consent and someone chose to contest the rightness of the intervention. ${ }^{3}$

While advocacy seems to be a possible solution, there are very few trained advocates available so far and the British model is that of a social best friend, rather than an advocate in law. ${ }^{+}$

\section{The present situation for those over 16 who cannot give consent}

With better lifestyles for those with intellectual handicap, involving choice making, taking risks, and standing by the consequences of personal decisions, many who are mildly, moderately, and even severely handicapped can make a simple choice if the situation is explained to them in terms they understand by someone they know and trust. Their vulnerability, however, must never be exploited by the unscrupulous who, by undue persuasion, may bias the choice that is made. Research is now being focused on the characteristics of the dialogue that allows maximum transfer of information and understanding.

There are times, however, when consent given by the handicapped person needs to be overruled. Such a person may feel very strongly about a certain matter and express their views but may not be able to see the full implications of what they are saying. They may have difficulty in long term planning and can only see the immediate future. The need to move from home when parents can no longer care may be essential, for example, but may be in direct opposition to the views of the handicapped person. They may refuse to consent to an operation on the basis that it might hurt. When such intervention is imperative and not controversial this lack of consent may be overridden using the doctrine of necessity.

At other times, naivety of the handicapped person may be misused in procedures that are nothing more than deceitful. Seclusion in a locked room is by definition done without consent and is a procedure that is safeguarded by rules and regulations in every district health authority. Some residences have a system whereby two door handles must be used simultaneously to open the door of such a room. If the client cannot operate the two door handles, then he is effectively secluded but may not be protected by the rules, an exploitation of his simplicity.

The position that we are in at present is clearly unsatisfactory. A substantial minority of people with intellectual handicap will never be able to give consent for themselves by virtue of the severity of 
their handicap or because of superimposed mental illness. The legal vacuum seems absolute and yet it is so little understood that time wasting procedures, such as asking parents to sign consent forms for adults, still continue. In the absence of consent of the person with intellectual handicap, the doctor acts 'in good faith' and shows 'a duty of care'. This applies to all care givers throughout the service and not only to the medical profession. It is, of course, good practice to obtain the agreement (but not the consent) of the next of kin, but there is no reason to hold up an emergency intervention until a relative can be found.

Where several lines of action are reasonable and possible and there is disagreement between the care giver and the family, then the care giver would be wise to seek further professional opinion with the family and to proceed cautiously. Often these issues are more social than medical-for example, about moving from long stay hospital to a house in the community, about expression of sexuality, and about risk taking in sporting holidays or road crossing programmes.

Most medical interventions are non-controversial but for high risk or doubtful outcome procedures the surgeon or physician would be wise to proceed only when he has the backing of a second or even a third professional opinion. Should the procedure involve research, with little or no benefit to the patient, be controversial, or have social as well as medical repercussions, ${ }^{5-7}$ such as sterilisation with or without abortion, full consultation with the legal profession and with the ethics committees are essential. Without this the medical profession must expect to be confronted by non-medical personnel and those representing the human rights movements, whatever the age of the patient.

\section{The age of enlightenment}

The vast majority of consent dilemmas can be overcome by resorting to wider medical consultation, involving the family, ethics committees, and occasionally the law, but a lot is left to the discretion of the caring personnel. There is, however, reason to hope for legal clarification soon. ${ }^{8}$ In a recent case where sterilisation was requested for a women with profound intellectual handicap and where the medical opinions for sterilisation were almost unaniumous, responsibility for the ultimate decision was passed from the High Court to The Court of Appeal and thence to The House of Lords. It is to be hoped that out of this expensive and time consuming exercise, rules will soon emerge that can be used in future similar situations. It may be that a hierarchial system is developed whereby straightforward deci- sions of minor import are decided at the grass roots level and with involvement of the family. Decisions of greater complexity may be dealt with at the level of the district health authority and the most complex by a committee with medical, legal, ethical, and lay representation. A similar committee is already set up in New York. ${ }^{9}$ Whatever the details, almost certainly the overriding philosophy will be to 'act in the best interests of the patient', however complex are the variables.

It must, of course, remain essential that the decision for one patient will not become the slippery slope for others. It is important that controversial decisions are not promoted on the basis of racial hygiene: it is a matter of ensuring that people who are legally incompetent have the best possible decisions made for them in the light of current knowledge.

\section{Action that can be taken now}

There is much to be done with what we know already. Each health authority should ensure that day to day procedures, in the accident and emergency department for example, acknowledge the rights of the patient, understand the concept of legal competence, the role of the care giver, and the decision making responsibility of the doctors. Explanation and education for medical students, doctors, and nurses are essential. A leaflet on every notice board in wards and departments, given to all new doctors and put in outpatient letters where the patient is known to be legally incompetent can outline the current situation and where to go for advice (TR Gould, J Bicknell, unpublished). Each health authority must be encouraged to adopt whatever procedure emerges from the current legal deliberations. Most ethics committees look at only research at present, but may in the future be required to look at clinical decisions in the absence of consent. Above all, the practicalities need to be so straightforward for outpatients and inpatients at ward and departmental level that legal incompetence does not become yet another reason for those with intellectual handicaps to be seen as awkward customers of the health service.

\footnotetext{
References

1 Gillon R. Where respect for autonomy is not the answer. Philosophical medical ethics. Br Med $J$ 1986;292:48-9.

2 Memorandum by the Law Society's Mental Health Sub Committee, Decision making and mental incapacity: a discussion document. London: The Law Society, 1989.

3 Dyer C. Judges cast doubt on law of consent. Guardian 1989 Jan 17:1.

4 Institute of Medical Ethics. Consent and the incompetent. Bulletin of the Institute of Medical Ethics 1989;47:3.
} 


\section{Bicknell}

${ }^{5}$ Royal College of Psychiatrists. Sterilisation and mentally handicapped people. Psychiatric Bulletin 1989;13:215.

- Royal College of Psychiatrists. Interim guidelines on consent to medical and surgical treatment, contraception, sterilisation and abortion in the mentally handicapped. The Bulletin of the Royal College of Psychiatrists 1986;10:1894.

7 Gillon R. On sterilising severely mentally handicapped people. J Med Ethics 1987;13:59-61.

${ }^{8}$ Bingley W. Competency and consent to medical treatment. Report of Mencap working party. London: Mencap, 1989.
${ }^{9}$ Clarence J, Sundram JD. Informed consent for major medical treatment of mentally disabled people. $N$ Engl J Med 1988;318: 1368

D J BICKNELL St George's Hospital Medical School, Cranmer Terrace, Tooting, London SW17 ORE 